\title{
Use of $\mathrm{CO}_{2}$ in video assisted thoracic surgery and single-lumen endotracheal tube-a new less invasive approach
}

\author{
Javier Gallego-Poveda, Nuno Carvalho Guerra, Catarina Carvalheiro, Hugo Ferreira, André Sena, Nádia \\ Junqueira, Tiago Rodrigues Velho, Ângelo Nobre \\ Cardiothoracic Surgical Department, Santa Maria University Hospital, Lisbon, Portugal \\ Contributions: (I) Conception and design: J Gallego-Poveda, NC Guerra; (II) Administrative support: C Carvalheiro, H Ferreira, A Sena; (III) \\ Provision of study materials or patients: TR Velho; (IV) Collection and assembly of data: C Carvalheiro, H Ferreira, A Sena; (V) Data analysis and \\ interpretation: J Gallego-Poveda, NC Guerra; (VI) Manuscript writing: All authors; (VII) Final approval of manuscript: All authors. \\ Correspondence to: Javier Gallego-Poveda. Cardiothoracic Surgical Department, Santa Maria University Hospital, Centro Hospitalar Lisboa Norte. \\ Avenida Egas Moniz, 1649 Lisbon, Portugal. Email: drjaviergallego@me.com.
}

\begin{abstract}
Carbon dioxide $\left(\mathrm{CO}_{2}\right)$ has been extensively used to allow laparoscopic procedures, due to its extensive advantages in obtaining a fairly innocuous pneumoperitoneum to allow visceral dissection. Its use in video assisted thoracic surgery (VATS) has seldom been described. We present our experience in more than 100 patients, operated for various thoracic pathologies, in whom we created a surgical pneumothorax to allow different surgeries to be undertaken.
\end{abstract}

Keywords: Video assisted thoracic surgery (VATS); carbon dioxide $\left(\mathrm{CO}_{2}\right)$; pneumothorax; minimally invasive ventilation

Submitted Nov 17, 2016. Accepted for publication Dec 09, 2016.

doi: $10.21037 /$ jtd.2017.01.53

View this article at: http://dx.doi.org/10.21037/jtd.2017.01.53

\section{Introduction}

Carbon dioxide $\left(\mathrm{CO}_{2}\right)$ has been extensively used to allow laparoscopic procedures, due to its advantages in obtaining a fairly innocuous pneumoperitoneum to allow visceral dissection. As advantages in its use, absence of a deleterious effect for the tissues it contacts with, and quick body resorption for small amounts have been cited.

Modern thoracic surgery nowadays relies on single lung ventilation, achieved through double lumen endotracheal tube or a bronchial blocker. The disadvantages of these two techniques are widely known, and include difficulty in accurately placing the double lumen tube, intra-operatory dislodgment of the tube, frequent need for fiber-optic bronchoscope support and need for more prolonged and deep anesthesia. Across many centers, experience with double lumen intubation is also not frequent.

Video assisted thoracic surgery (VATS) nowadays allows most thoracic procedures to be undertaken. The use of video has revolutionized all surgery, and thoracic surgery has benefited greatly from this technique.

Nevertheless, up until recently, VATS has made the use of selective lung ventilation mandatory, and surgeries which could be relatively easily accomplished with an open thoracotomy using a single tube are nearly impossible by VATS with a single tube.

In the last three years, our group has been using $\mathrm{CO}_{2}$ coupled with single tube tracheal intubation as a means to create a space in the pleural cavity in which instruments can be mobilized and operations undertaken. After surgery, any residual gas left in the pleural cavity is more easily absorbed by the pleural cavity, as has been known for many years since the development of laparoscopic surgery. This represents an enormous advantage in favor of using this technique, since frequently a chest drain can be avoided and hospital stay shortened.

We have been expanding the uses of this technique and believe it offers important advantages in several types of thoracic surgery, especially pneumothorax surgery. 


\section{Technique}

The patient is placed in supine position and after general anesthesia single lumen tracheal intubation is obtained. An arterial line (usually left radial artery) is placed. Depending on the surgery which will be undertaken, we use from one to three valved trocars. An incision is made in the appropriate place and the first trocar in introduced with the patient temporarily disconnected from the ventilator, to avoid lung laceration. We then start the $\mathrm{CO}_{2}$ insufflation at $3 \mathrm{~L} / \mathrm{min}$, with a pressure of 5 to $6 \mathrm{mmHg}$. If for some reason lung adhesions are present and no partial collapse is obtained, the $\mathrm{CO}_{2}$ insufflator may alarm high pressure, which leads us to reconsider the surgical approach.

Most of the times, a satisfactory partial lung collapse is obtained and the remaining trocars are introduced. Constant surveillance of the heart rhythm and invasive arterial pressure is undertaken by the anesthetist and the surgeon to detect early mediastinal shift. The usual signs of mediastinal shift in this situation are hypotension and bradycardia. Should any of these or other electrical or hemodinamical disturbances occur, the intra pleural pressure is allowed to normalize instantly through one of the valved trocars, and the $\mathrm{CO}_{2}$ pressure in the insufflator is diminished.

The surgery is performed in the usual way, and in the end, depending on the surgery, simple aspiration of the pleural space is performed with a nasogastric probe through the trocar, or chest drains are placed. The rest of the procedure is similar to the usual thoracoscopic surgery, and anesthesia is easily terminated, due to less profound sedation and less invasive ventilation performed.

\section{General advantages}

(I) Faster anesthesia;

(II) Single lumen tube ventilation (less invasive);

(III) Easier anesthesia;

(IV) No dependance on existence of fiber-optic bronchoscopy;

(V) No dependence on anesthetic experience with doublelumen intubation;

(VI) Less probability of lasting pneumothorax, quicker absorption of pneumothorax, allowing avoidance of chest drains in some situations;

(VII) Quicker recovery and earlier hospital discharge.

\section{General disadvantage}

Need of arterial invasive monitoring due to risk of mediastinal shift in selected cases.

\section{Special considerations according to the type of} surgery performed:

\section{Sympathectomy}

(I) Allows avoidance of chest tube drainage (the $\mathrm{CO}_{2}$ is aspirated at the end of the surgery);

(II) Allows earlier hospital discharge.

In sympathectomy, we do a $5 \mathrm{~mm}$ incision in the $3 \mathrm{rd}$ intercostal space and place a nylon stitch on that same incision for easy closure after trocar removal. We use a $5 \mathrm{~mm}$ valved trocar and initiate $\mathrm{CO}_{2}$ insufflation. We insert the $5 \mathrm{~mm}$ optic and then we do a second $5 \mathrm{~mm}$ incision on the 5 th intercostal space, place the another stitch and use a second valved trocar. After sympathetic nerve clipping, we place an apical nasogastric suction tube through the 5 th intercostal space incision, check that the $\mathrm{CO}_{2}$ is diminishing, ask the anesthetist to manually inflate the lung and remove both trocars, pulling the nasogastric suction probe. Residual $\mathrm{CO}_{2}$ is easily and quickly absorbed by the pleura (Figure 1).

\section{Pneumothorax/emphysema surgery}

(I) Greatly improves visualization of the bullae;

(II) Diminishes probability of leaving unresected bullae;

(III) Greatly facilitates localization of fistula.

Pneumothorax surgery is greatly facilitated with the use of $\mathrm{CO}_{2}$ insufflation. Besides all the advantages with the anesthetic management, the presence of some pressure on the diseased lung causes the bullae to be expanded, while the $\mathrm{CO}_{2}$ still allows for a generous space which allows the surgery to be undertaken. In the case of pleural fistulae, the maintenance of pressure on the airways, and the diseased lung, while maintaining a pleural space, allows very easy detection of the disrupted pleura with the use of irrigation of the pleural surface, something not easily done with double lumen ventilation. Due to the nature of the underlying disease, and the need for pleurectomy and the associated risk of bleeding, we always leave an apical and a basal drain (Figure 2).

\section{Pericardial and mediastinal cysts, mediastinal node biopsy}

(I) Avoidance of sternotomy and chest drain.

In simple pericardial and mediastinal cysts and nodes, $\mathrm{CO}_{2}$ allows for easy resection of the lesions. Should hemostasis prove to be perfect at the end of the resection, a simple suction of the pleural cavity, as described earlier for sympathectomy, may be performed, and a chest drain 


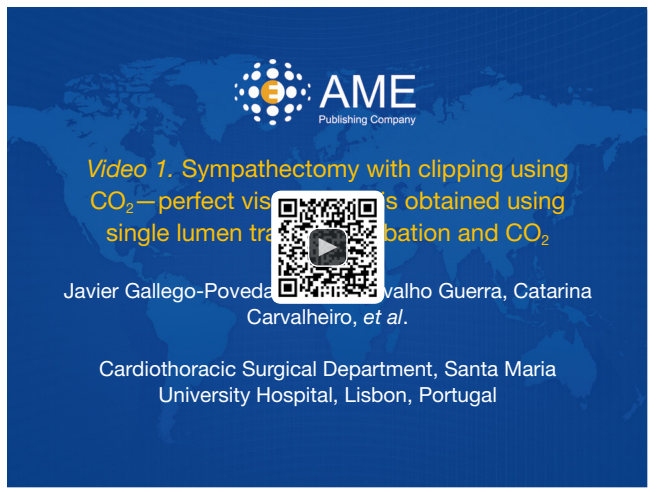

Figure 1 Sympathectomy with clipping using $\mathrm{CO}_{2}$ - perfect visualization is obtained using single lumen tracheal intubation and $\mathrm{CO}_{2}$ (1). Available online: http://www.asvide.com/articles/1359

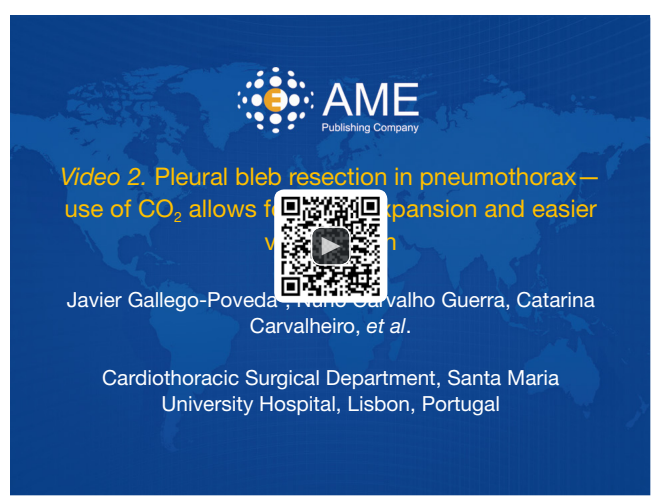

Figure 2 Pleural bleb resection in pneumothorax-use of $\mathrm{CO}_{2}$ allows for blebs expansion and easier visualization (2). Available online: http://www.asvide.com/articles/1361

avoided. Avoidance of sternotomy and chest drains allows for drastically diminished hospital stay.

\section{Pericardial effusion/tamponade-creation of pleuropericardial window}

(I) Allows quicker and less profound anestesia in unstable patients.

In selected cases of pericardial effusion and tamponade, if a pleuropericardial window is being considered as an option in unstable patients, $\mathrm{CO}_{2}$ inflation is a safe choice, allowing quicker and safer anesthesia. In unstable cases, the $\mathrm{CO}_{2}$ insufflation pressure used is lower $(3 \mathrm{mmHg})$. These patients are operated with a pillow under the right side of the thorax to slightly rotate the thorax to the contralateral side. Chest drains, which may be intrapericardial, are always placed.

\section{Nuss surgery for pectus excavatum}

(I) Allows safe passage of Nuss dissector and bar;

(II) Does not preclude use of chest drain due to contralateral pneumothorax.

While performing Nuss surgery for correction of pectus excavatum, $\mathrm{CO}_{2}$ insufflation is very helpful.

An arterial line placement is standard procedure in our group when the Nuss procedure is done.

The creation of a pneumothorax allows for safe passage of the Nuss dissector and the bar, and is still performed by most surgeons performing Nuss procedures. $\mathrm{CO}_{2}$ inflation allows avoidance of double lumen intubation, which is very important in patients which are frequently young and have small diameter airways.

Due to the fact that $\mathrm{CO}_{2}$ usually permeates through the pathway created by the dissector to the contralateral hemithorax, we always leave a single chest drain on the right side of the patient. We found the gas on the left hemithorax is not easily aspirated from the right side during the surgery and takes some time to permeate to the right side again. The chest drain is normally left for three days to allow complete $\mathrm{CO}_{2}$ absorption and aspiration, (the usual hospital stay due to pain control Nuss surgery normally necessitates), so $\mathrm{CO}_{2}$ inflation does not increase hospital stay in this setting.

\section{Atrial fibrillation and left atrial appendage occlusion}

Thoracoscopic ablation of atrial fibrillation is always done with arterial line placement.

$\mathrm{CO}_{2}$ inflation assures absence of lung inflation during very delicate and risky cardiac manipulation. Sudden lung inflation, which may occur during double lumen intubation due to dislodgment of the endotracheal tube with catastrophic consequences, is avoided by use of $\mathrm{CO}_{2}$ inflation. Bilateral chest drains are always placed in this procedure.

\section{Acknowledgements}

None. 


\section{Footnote}

Conflicts of Interest: The authors have no conflicts of interest to declare.

\section{References}

1. Gallego-Poveda J, Guerra NC, Carvalheiro C, et al. Sympathectomy with clipping using $\mathrm{CO}_{2}-$ perfect

Cite this article as: Gallego-Poveda J, Guerra NC, Carvalheiro C, Ferreira H, Sena A, Junqueira N, Velho TR, Nobre Â. Use of $\mathrm{CO}_{2}$ in video assisted thoracic surgery and single-lumen endotracheal tube-a new less invasive approach. J Thorac Dis 2017;9(4):903-906. doi: 10.21037/jtd.2017.01.53 visualization is obtained using single lumen tracheal intubation and $\mathrm{CO}_{2}$. Asvide 2017;4:062. Available online: http://www.asvide.com/articles/1359

2. Gallego-Poveda J, Guerra NC, Carvalheiro C, et al. Pleural bleb resection in pneumothorax-use of $\mathrm{CO}_{2}$ allows for blebs expansion and easier visualization. Asvide 2017;4:063. Available online: http://www.asvide.com/ articles/1361 